\title{
A comparative assessment of two modelling approaches for simulation of nutrient dynamics in river basins using case studies in Japan and Australia
}

\author{
$\underline{\text { M.J. Alam }}^{1}$ and D. Dutta ${ }^{2}$ \\ ${ }^{1}$ University of Southern Queensland, Toowoomba, QLD4350, Australia \\ ${ }^{2}$ CSIRO Land and Water, Canberra, Australia \\ Email: Mdjahangir.alam@usq.edu.au
}

\begin{abstract}
The modelling of nutrient dynamics in a river basin is a challenging task. This type of modelling requires huge amount of datasets to describe the dominant catchment biogeochemical processes and in-stream nutrient dynamics. In traditional modelling using a conceptual approach, the inherent processes are simplified. On the other hand, the process based modelling approach aims to represent catchment characteristics in a detailed manner. The aim of this study is to evaluate the performance of two modelling approaches, subcatchment based semi-conceptual approach and raster-based process-oriented distributed modelling approach, for simulation of nutrient dynamics at a river basin scale. The model has been applied in two river basins in Australia and Japan.

In the sub-catchment based modelling, the study area is divided into a number of sub-catchments. The model estimates nutrient export from each sub-catchment in terms of soil bound nutrient associated with soil erosion and dissolved nutrients with runoff. The estimation of soil erosion has been carried out using universally used empirical equations RUSLE and MUSLE. The soil delivery ratio was used to determine the sediment yield from the catchments. The nutrient model takes account of nutrient generation process on the land surface and determine nutrient export via soil erosion and runoff using export functions. The fate of nutrient and transport process in river networks system has been described by solving advection-dispersion equation with chemical reaction.
\end{abstract}

The raster-based model was configured into a cluster of square grids with appropriate size, where each grid was defined with a set of parameters that represent catchment characteristics. The pollution from land surface to the in-stream release in response to hydro-climatic and land use management practice are modelled. In this modelling approach, the soil erosion model replaced the empirical equations used in sub-catchment based model with process based equations that take into account both rainfall and overland flow impacts on soil erosion. The sediment yield was determined based on transport capacity. The modelling process combined the simulation of surface and river components dynamically. By Describing hydrologic process, hill slope soil erosion and nutrient dynamics in each grid on the land surface, the model estimates catchment nutrient release and its fate during transport in river network system. At the river-surface interface the lateral flow and pollutant load exchange are determined. The model solves the physical transport equation with catchment chemical reaction processes to computes nutrient concentration at each river grid.

The case study area the Saru River in Japan consists of 17 sub-catchments covering a catchment area of 1,350 $\mathrm{km}^{2}$. The river carried huge amount of sediment and nutrient fluxes during two consecutive flooding events, in 2009, which were modelled in this study. Hourly interval observed data was gathered for the model calibration and validation. On the other hand, the $2^{\text {nd }}$ case study area was located in Latrobe Basin in Gippsland, Australia. The upper catchment of the Latrobe River was modelled in this study for long term simulations of sediment and nutrient fluxes.

The model shows better performance in simulating short term flooding events for the Saru River. Due to lack of data the performance matrix for the Latrobe River are relatively low. It is found that the process based model is highly effective in providing higher resolution modelling outcome. An investigation on the improvement of the process based equations may enhance model performance further.

Keywords: Nutrient pollutions, lumped and distributed modelling, water quality, hydrologic model, river basin 
Alam \& Dutta, Comparative assessment of two modelling approaches for simulation of nutrient dynamics....

\section{INTRODUCTION}

The quantification of nutrient pollution is one of the challenging tasks in water resources management (Panagopoulos et al., 2011). Due to the ongoing development pressures on land use and changing hydroclimatic conditions, the pollution level in surface and ground waters have increased in many parts of the world ( $\mathrm{Lu}$ and Li, 2011; Dutta et al., 2009). To provide confidence in decision making for effective management, the modelling of pollution dynamics need to be done at high spatial and temporal resolutions with realistic details of catchment characteristics. However, in many cases the nutrient modelling is carried out using conceptually simplistic methods such as event mean concentration (EMC) or export coefficient methods, which may not fulfill the need for current situation (Tzoraki et al., 2014). On the other hand, the process based model provides a greater details in prediction of pollution level at higher resolutions. MIKESHE (Abbott et al., 1986a,b) and IISDHM (Dutta et al., 2000) are two of the distributed models, which have been used widely in many hydrological studies. This study has developed a nutrient dynamics model within the framework of IISDHM and a comparative assessment of both sub-catchment and raster based modelling approaches has been carried out applying the model in two river basins. The performance of the process based modeling has been compared with conceptual and empirical equation based methods.

\section{METHODS}

The common hydrological modelling platform is the IISDHM for this study, which has been used to generate the catchment runoff and river flow. The distributed hydrological model IISDHM was originally developed at the Institute of Industrial Sciences of the University of Tokyo, Japan (Dutta, et al., 2000). Since its development, the tool has been used widely in many countries for simulation of surface water quantity (Jha, et al., 2000). Within the framework, the modules for sediment and nutrient components were added to build the process-based distributed nutrient model for raster based analysis of nutrient dynamics at a river basin scale (Figure 1). The sub-catchment based model uses the output of hydrological model at sub-catchment levels. The components of both models are presented below.

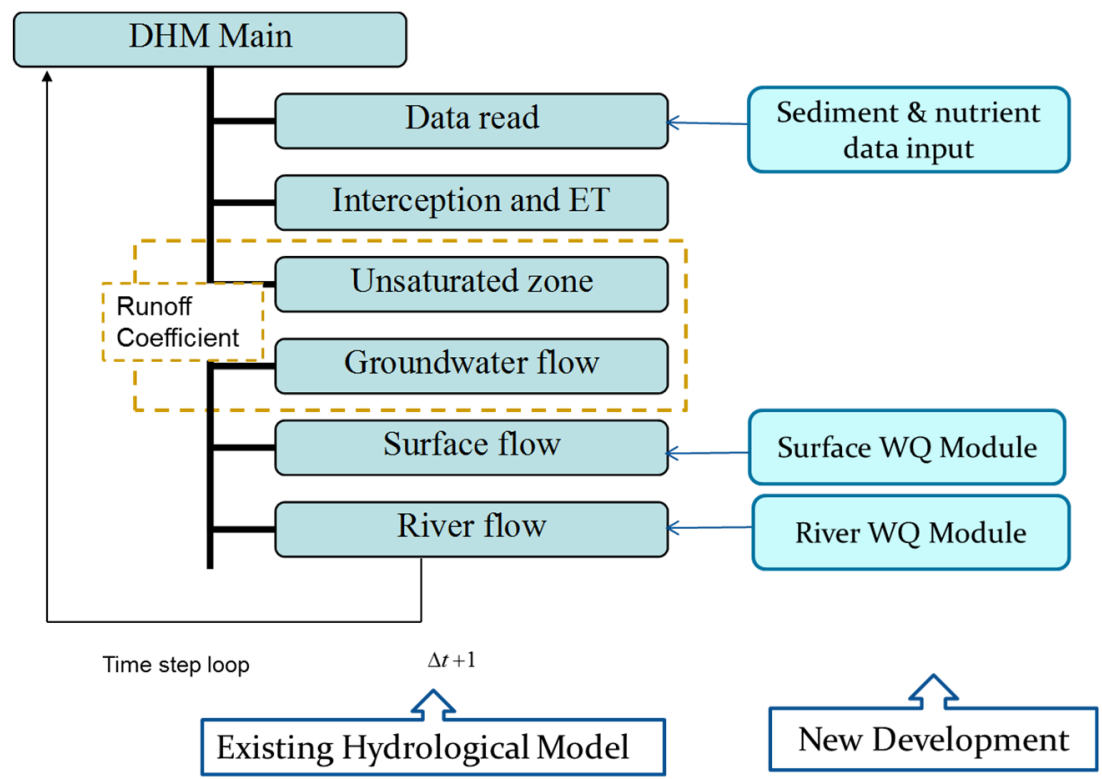

Figure 1. The structure of IISDHM and the new components of sediment and nutrient dynamics

\subsection{Overview of the sub-catchment based model}

In the sub-catchment based modelling, the study area is divided into a number of sub-catchments (Alam and Dutta, 2016; Alam and Dutta, 2013). The model estimates nutrient export from each sub-catchment in terms of soil bound nutrient associated with soil erosion and dissolved nutrients with runoff. The fate of nutrient and transport process in river networks system has been described by solving advection-dispersion equation with chemical reaction. The estimation of soil erosion has been carried out using Universal Soil Loss Equation (USLE) (Wischmer and Smith, 1978) based models RUSLE (Renard and Freimund, 1994) and MUSLE (Williams and Berndt, 1977; Bhattarai and Dutta, 2008; Kabir et al., 2011). The RUSLE method was applied to the Saru River Basin and the MUSLE was applied to the Latrobe River Basin. The soil delivery ratio was 
Alam \& Dutta, Comparative assessment of two modelling approaches for simulation of nutrient dynamics....

used to determine the sediment yield from the catchments. The nutrient model takes account of nutrient generation process on the land surface and determine nutrient export via soil erosion and runoff using export functions.

\subsection{Overview of the raster-based model}

The raster-based model was configured into a cluster of grids with appropriate size, where each grid was defined with a set of parameters that represent catchment characteristics. The pollution from land surface to the in-stream release in response to hydro-climatic and land use management practice are modelled. In this modelling approach, the soil erosion model replaced the empirical equations used in sub-catchment based model with process based equations that accounts for both rainfall and overland flow impacts on soil erosion. The sediment yield was determined based on transport capacity. The modelling process combined the simulations of surface and river components dynamically. Describing 1) hydrologic process, 2) hill slope soil erosion and 3) nutrient dynamics in each grid on the land surface, the model estimates catchment nutrient release and its fate during transport in river network system. At the river-surface interface the lateral flow and pollutant load exchange are determined. The model solves the transport equation for physical and chemical reaction to computes nutrient concentration at each river grid (Alam and Dutta, 2012).

\subsection{The approach used for performance evaluation}

The performance of the two models has been evaluated using statistical measures and expressed qualitatively. The evaluation criteria are shown in Table 1.

Table 1. Performance evaluation criteria

\begin{tabular}{|l|c|c|c|c|c|c|}
\hline Parameter & $\begin{array}{c}\text { Very } \\
\text { Good }\end{array}$ & Good & Satisfactory & Bad & Worse & Worst \\
\hline PBIAS $( \pm)(\%)$ & $0-10$ & $11-20$ & $21-30$ & $31-40$ & $41-50$ & $>50$ \\
\hline NSE and $r^{2}$ & $0.90-1.0$ & $0.80-0.89$ & $0.70-0.79$ & $0.60-0.69$ & $0.50-0.59$ & $<0.5$ \\
\hline
\end{tabular}

\subsection{Case study areas}

Two case study areas; Saru River and Latrobe basins, were selected for this study in order to test the models in two distinct hydro-climatic condition. The Saru River with a catchment area of 1,350 km2 is located in Hokkaido prefecture in Japan. The catchment is predominantly forest. The land use pattern includes forest $92 \%$, agricultural area $3 \%$ and minor urban features. This river carries huge amount of sediment and nutrient discharge during heavy floods. High intensity measurements were carried out during two consecutive high flood events, which were used in this study. The other case study the Latrobe River, drains a catchment area of $4500 \mathrm{~km} 2$, is situated in the Gippsland region of Victoria in Australia. In contrast to the Saru River the Latrobe River is situated in a dry and semi-arid region. The flow in the river is relatively very low. Nutrient pollution is a common problem and is a threat for the downstream Gippsland lakes, a Ramsar site and socioeconomically significant wetland system in the region. The geographic locations of the two study sites are shown in Figure 2.
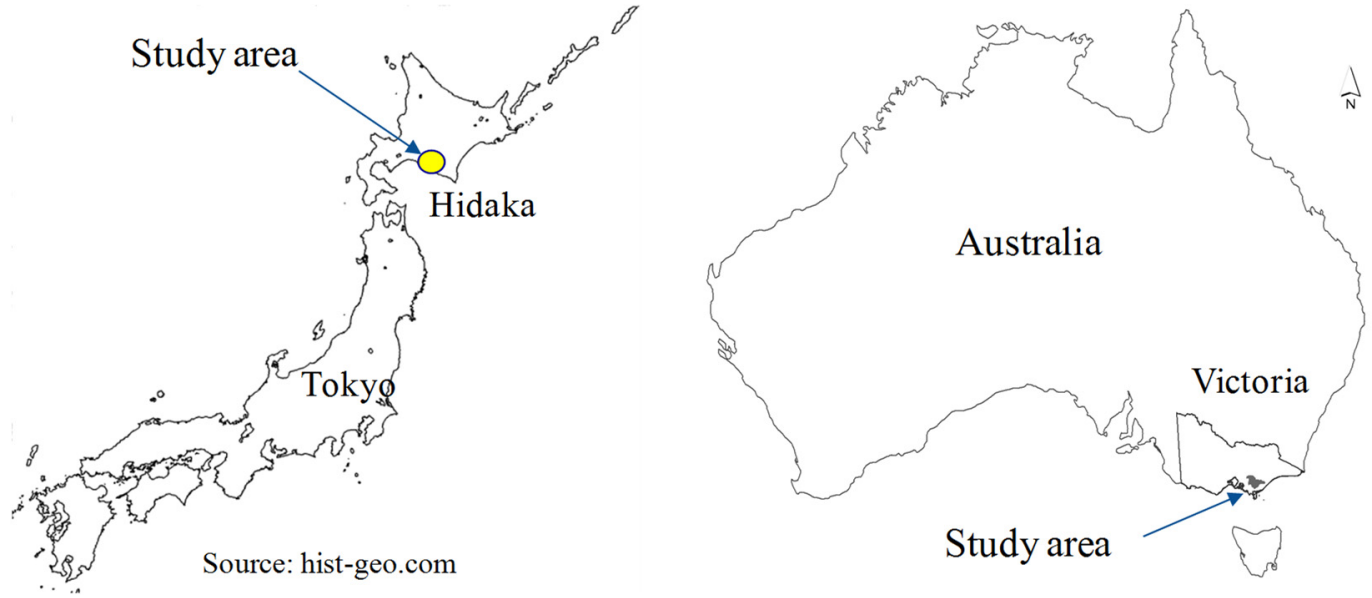

Figure 2. Locations of two study areas 
Alam \& Dutta, Comparative assessment of two modelling approaches for simulation of nutrient dynamics....

\section{RESULTS AND DISCUSSION}

The two models have been calibrated and validated against observed data. A large flood event in 2009 was used in model parameter calibration for the Saru River and a relatively smaller magnitude flood event in the previous month of the same year was used for validation. The data was available at hourly time scale. For the Latrobe River, the calibration period was from June in 2007 to January 2008 and the validation period was from September 2009 to end of July 2011. However, the data was limited for the Latrobe River. A number of comparisons between the simulated outputs by the two models and observed data during the model calibration and validation at the two study areas, Saru River and Latrobe River are plotted in Figure 3 and Figure 4, respectively.

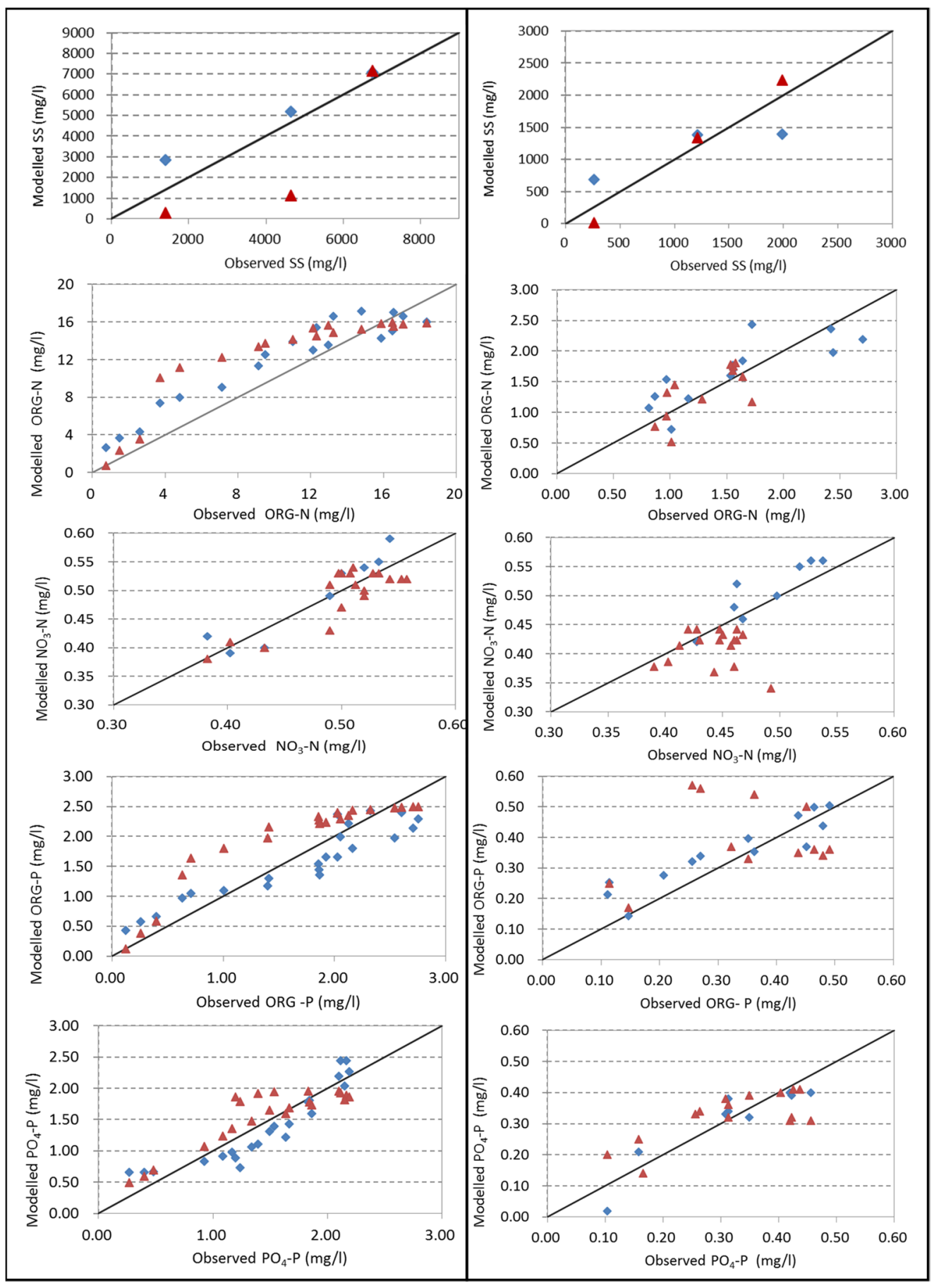

(a) Calibration

(b) validation

Figure 3. Comparison of raster based and sub-catchment based model results for the Saru River (Red- Sub-catchment based model, Blue- Raster based model) 
Alam \& Dutta, Comparative assessment of two modelling approaches for simulation of nutrient dynamics....

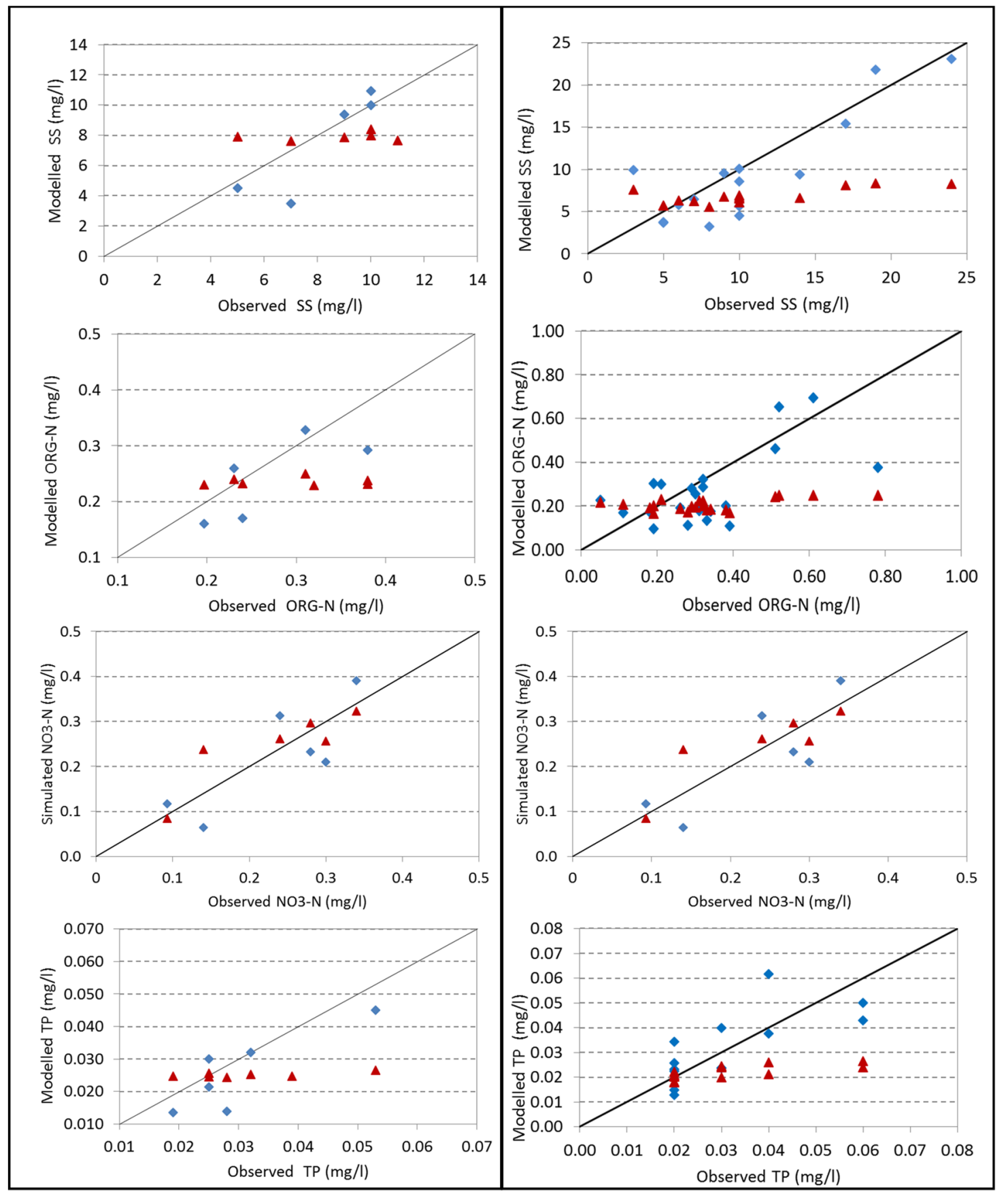

(a) Calibration

(b) Validation

Figure 4. Comparison of raster based and sub-catchment based model results for the Latrobe River (Red- Sub-catchment based model, Blue- Raster based model)

In general, the grid based approach performed well compared to the sub-catchment based approach. The PBIAS is improved from Bad to Very Good status, and NSE and $r^{2}$ from good to Very Good in the raster-based approach. The validation results show better performance for sediment concentration in the sub-catchment approach. It is worth noting that the simulated sediment concentration by the sub-catchment model were analyzed at a daily time scale, whereas, hourly timescale was used for analysing the performance of the rasterbased model. The similar performance is observed for other parameters as shown in Table 2. The inorganic nutrient was well simulated by the raster-based modelling. 
Alam \& Dutta, Comparative assessment of two modelling approaches for simulation of nutrient dynamics....

The performance of the models in Latrobe River was less satisfactory compared to Saru River. This was mainly due to non-availability of sufficiently detailed data for comparison. Despite this, the grid based model shows better performance compared to the sub-catchment based model as shown in Table 3.

Table 2. Model performances for the Saru River

\begin{tabular}{|c|c|c|c|c|c|c|c|}
\hline \multirow{3}{*}{ Parameter } & \multirow{2}{*}{ Model } & \multicolumn{3}{|c|}{ Calibration } & \multicolumn{3}{c|}{ Validation } \\
\cline { 3 - 8 } & & PBIAS & NSE & $r^{2}$ & PBIAS & NSE & $r^{2}$ \\
\hline \multirow{3}{*}{$S S$} & Sub & 33.00 & 0.80 & 0.80 & -3.51 & 0.97 & 0.99 \\
\cline { 2 - 9 } & Grid & -3.23 & 0.98 & 0.98 & -13.24 & 0.85 & 0.99 \\
\hline \multirow{3}{*}{$N O_{3}-N$} & Sub & -18.07 & 0.70 & 0.73 & 0.51 & 0.42 & 0.87 \\
\cline { 2 - 9 } & Grid & -13.81 & 0.83 & 0.91 & -6.52 & 0.63 & 0.66 \\
\cline { 2 - 9 } & Sub & 1.00 & 0.67 & 0.60 & 1.81 & 0.47 & 0.60 \\
\hline \multirow{2}{*}{$O R G-P$} & Grid & -2.83 & 0.75 & 0.90 & -3.91 & 0.39 & 0.83 \\
\cline { 2 - 9 } & Grid & -17.98 & 0.72 & 0.79 & 6.99 & 0.52 & 0.57 \\
\hline \multirow{2}{*}{$P O_{4}-P$} & Sub & -6.96 & 0.78 & 0.66 & -12.52 & 0.69 & 0.82 \\
\cline { 2 - 9 } & Grid & 5.11 & 0.80 & 0.83 & 1.81 & 0.82 & 0.84 \\
\hline
\end{tabular}

Table 3. Model performances for the Latrobe River

\begin{tabular}{|c|c|c|c|c|c|c|c|}
\hline \multirow{2}{*}{ Parameter } & \multirow{2}{*}{ Model } & \multicolumn{3}{|c|}{ Calibration } & \multicolumn{4}{c|}{ Validation } \\
\cline { 2 - 8 } & & PBIAS & NSE & $r^{2}$ & PBIAS & NSE & $r^{2}$ \\
\hline \multirow{3}{*}{$S S$} & Sub & 8.77 & -0.10 & 0.04 & 35.29 & -0.23 & 0.53 \\
\cline { 2 - 9 } & Grid & 6.52 & 0.28 & 0.81 & 10.26 & 0.66 & 0.74 \\
\hline \multirow{2}{*}{$T P$} & Sub & 20.41 & -0.29 & 0.45 & 30.38 & -0.22 & 0.52 \\
\cline { 2 - 9 } & Grid & 14.33 & 0.53 & 0.72 & -0.66 & 0.47 & 0.53 \\
\hline \multirow{2}{*}{$O R G-N$} & Sub & 19.84 & -0.73 & 0.01 & 36.95 & -0.39 & 0.29 \\
\cline { 2 - 9 } & Grid & 10.77 & 0.30 & 0.56 & 16.93 & 0.15 & 0.38 \\
\hline \multirow{2}{*}{$N O_{3}-N$} & Sub & -1.87 & 0.76 & 0.77 & 9.09 & 0.43 & 0.60 \\
\cline { 2 - 9 } & Grid & 8.27 & 0.66 & 0.73 & 23.35 & -2.20 & 0.03 \\
\hline
\end{tabular}

\section{CONCLUSIONS AND RECOMMENDATIONS}

This study compared the performances of sub-catchment and grid based modelling approaches. The subcatchment based modelling approach was relatively easy to build using widely used empirical equations for sediment modelling. However, the performance of the model was less satisfactory. The replacements of the empirical methods with process based representation have improved the model accuracy. The key limitations of this study was in the availability of high resolution water quality data. An investigation on the improvement of the process based export function may further enhance the model performance.

\section{ACKNOWLEDGMENTS}

The study was undertaken as part of the PhD project at Monash University, Australia. The data used in this study was accessed from the Kitami Institute of Technology, Japan for the Saru River and Australian government agencies' websites for the Latrobe River. Authors greatly acknowledge the contributions of these various organisations and individuals who have supported this study directly or indirectly. 
Alam \& Dutta, Comparative assessment of two modelling approaches for simulation of nutrient dynamics....

\section{REFERENCES}

Abbott, M.B., Bathurst, J.C., Cunge, J.A., O'Connell, P.E. and Rasmussen, J. (1986a). An introduction to the European Hydrological System - Systeme Hydrologique Europeen, 'SHE, 1: History and philosophy of a physically based modelling system, Journal of Hydrology., 87:45-59.

Abbott, M.B., Bathurst, J.C., Cunge, J.A., O'Connell, P.E. and Rasmussen, J. (1986b). An introduction to the European Hydrological System - Systeme Hydrologique Europeen, SHE, 2: Structure of a physically based distributed modelling system, Journal of Hydrology, 87:67- 77.

Alam, M.J. and Dutta, D. (2016). A sub-catchment based approach for modelling nutrient dynamics and transport at a river basin scale, Water Resources Management, 30:5455-5478.

Alam, M.J. and Dutta, D. (2013). Predicting climate change impact on nutrient pollution in waterways: a case study in the upper catchment of the Latrobe River, Australia, Ecohydrology, 6(1):73-82.

Alam, M. J. and Dutta, D. (2012). A process-based and distributed model for nutrient dynamics in river basin: development, testing and applications, Ecological Modelling, 247:112- 124.

Bhattarai, R. and Dutta, D. (2008). A Comparative Analysis of Sediment yield Simulation by SEDD, MUSLE and a Process based model in Thailand, Hydrological Sciences Journal, 53(6):1253-1269.

Cook, F.J., Jordan, P.W., Waters, D.K. and Rahman, J.M. (2016). WaterCAST - Whole of Catchment Hydrology Model An Overview, 18th World IMACS / MODSIM Congress, 13-17 July, Cairns, Australia, viewed 1 November 2009, http://mssanz.org.au/modsim09.

Dutta, D., Nakayama, K. (2009). Effects of spatial grid resolution on river flow and surface inundation simulation by physically based distributed modeling approach. Hydrological Processes. 23:534-545.

Dutta, D, Herath, S. and Musiake, K. (2000). 'Flood inundation simulation in a river basin using a physically based distributed hydrologic model', Journal of Hydrological Processes, 14:497-519.

Jha, R., Herath, S. and Musiake, K. (2000). River network solution for a distributed hydrological model and applications', Journal of Hydrological Processes, 14:575-592.

Kabir, M.A., Dutta, D. and Hironaka, S. (2011). Process-based Distributed Modeling Approach for Analysis of Sediment Dynamics in a River Basin, Hydrology and Earth System Sciences, 15(4):1307-1321

Lu, X.X. and Li, S. (2011). Seasonal changes of nutrient fluxes in the Upper Changjiang basin: An example of the Longchuanjiang River, China, Journal of Hydrology, 405:344-351.

Perraud, JM, Seaton, SP, Rahman, JM, Davis, GP, Argent, RM \& Podger, G.M. (2005). The architecture of the E2 catchment modelling framework, in A Zerger, RM Argent (eds), MODSIM 05 International Congress on Modelling and Simulation, Melbourne, 690-696.

Panagopoulosa,Y, Makropoulosa, C \& Mimikou, M. (2011). Diffuse Surface Water Pollution: Driving Factors for Different Geoclimatic Regions, Water Resour Manage, 25:3635-3660.

Tzoraki, O.A., Dörflinger,G., Kathijotes, N. and Kontou, A. (2014). Nutrient-based ecological consideration of a temporary river catchment affected by a reservoir operation to facilitate efficient management, Water Science and Technology, 69(4):847-854.

Renard KG and Freimund JR (1994). Using monthly precipitation data to estimate the R-factor in the revised USLE, Journal of Hydrology, 157:287-306.

Weischmer, W.H., Smith, D.D., (1978). Predicting rainfall erosion losses - a guide to conservation planning, US Department of Agriculture. Agricultural Handbook. p282.

Williams, J.R., Berndt, H.D., (1977). Sediment yield prediction based on watershed hydrology. Transaction of American Society of Agricultural Engineers. 20:1100-1104. 